\title{
PERSPEKTIF AWAM DALAM IMPLEMENTASI ELISITASI KEBUTUHAN MENGGUNAKAN USER PERSONA
}

\author{
Evi Dwi Wahyuni,Wahyu Andhyka Kusuma, Haidar Rais Abdillah, Helda Yuliani Sari \\ Program Studi Teknik Informatika, Fakultas Teknik, Universitas Muhammadiyah Malang, \\ Jalan Raya Tlogomas No.246 Malang \\ Email:evi.d.wahyuni@gmail.com, kusuma.wahyu.a@gmail.com, haidarraisabd@gmail.com, \\ hyulianisari@gmail.com
}

(Diterima: 30 April 2020 ,direvisi: 11 Juni 2020, disetujui: 8 Agustus 2020)

\begin{abstract}
Software development is demanded to make it easier for users to meet the needs of users who have not yet resolved in the system. one approach that is quite effective is Persona which is a Human Computer Interaction (HCI) technique by gathering information about users to collect their characteristics. HCI here is the process of interaction between humans and computers.. The main key to HCI is to have to deepen the user experience (UX) and also the user interface (UI) because an effective HCI based on User Persona identification can improve software quality. The purpose of this study is to identify some information that is less effective by designing user-persona methods to make HCI more effective. This research implements the Cooper Method although this method is quite difficult to do with various identification steps and validation of one channel in one phase which makes the weak point. The Persona technique in the Cooper method is suitable to be implemented in this study because there is research on PL by identifying behavior patterns of PL users that are compatible with HCI needs to be more effective. The various identification steps show more accurate results. Modifications made by the author in this study to ensure validation in each step of the Cooper method with an iterative model. Effective HCI based on User Identification can improve UX and UI quality.
\end{abstract}

Keywords: human computer interaction, personas, software, requirements elicitation

\begin{abstract}
ABSTRAK
Pengembangan perangkat lunak yang dituntut untuk memudahkan pengguna dalam memenuhi kebutuhan pengguna berdasarkan permasalahan yang belum terselesaikan dalam sistem. salah satu ancangan yang cukup efektif adalah Persona yang merupakan teknik Human Computer Interaction (HCI) dengan cara mengumpulkan informasi tentang pengguna untuk memahami karakteristik mereka. HCI disini adalah proses interaksi antara manusia dengan computer. Kunci utama HCI ialah harus mendalami user experience (UX) dan juga user interface (UI) dikarenakan HCI yang efektif berdasarkan identsifikasi User Persona dapat meningkatkan kualitas perangkat lunak. Tujuan dari penelitian ini adalah mengidentifikasi beberapa informasi yang kurang efektif dengan melakukan ancangan metode User Persona agar HCI lebih efektif. Penelitian ini mengimplementasikan Metode Cooper meskipun metode ini cukup sulit untuk dilakukan dengan langkah identifikasi yang beragam serta validasi satu alur dalam satu fase yang menjadikan titik lemahnya. Teknik Persona dalam metode Cooper cocok diimplementasikan dalam penelitian ini dikarenakan adanya penelitian terhadap PL dengan mengidentifikasi pola perilaku pengguna PL yang cocok dengan kebutuhan HCI agar lebih efektif. Langkah identifikasi yang beragam menunjukkan hasil yang lebih akurat. Modifikasi yang dilakukan penulis pada penelitian ini untuk memastikan validasi dalam setiap langkah pada metode Cooper dengan model iteratif. HCI yang efektif berdasarkan identifikasi User Persona dapat meningkatkan kualitas UX dan UI.
\end{abstract}

Kata Kunci: interaksi manusia komputer, persona , perangkat lunak, elisitasi kebutuhan 


\section{PENDAHULUAN}

Analisis kebutuhan merupakan bagian pengembangan perangkat lunak (PL) yang relatif mudah. Meskipun demikian, bagian ini merupakan titik vital dari pengembangan PL. Kebutuhan pengembangan PL yang salah diidentifikasi akan mengakibatkan kerugian yang sangat kompleks, termasuk membengkaknya anggaran dikarenakan tidak maksimalnya identifikasi kebutuhan pengembangan PL.

Dalam pengembangan PL memahami persyaratan kebutuhan sistem secara umum juga tidak dapat menghasilkan pengembangan PL yang ideal. Sehingga pengguna harus tetap dilibatkan dalam penggalian kebutuhan pengembangan PL. Setiap fase pengembangan perangkat lunak dituntut untuk memudahkan pengguna dalam penggunaannya selain itu dalam setiap tahapan memenuhi kebutuhan pengguna berdasarkan permasalahan yang belum terselesaikan dalam sistem. Salah satu pendekatan yang cukup efektif adalah Persona yang merupakan teknik Human Computer Interaction (HCI) dengan cara mengumpulkan informasi tentang pengguna agar memahami tentang karakteristik mereka. Human Computer Interaction (HCI) menggunakan sekumpulan proses dan kegiatan yang dimana melaluinya pengguna memanfaatkan dan berinteraksi dengan komputer. HCI merupakan teknik pengembangan untuk memastikan bahwa kegunaan produk perangkat lunak memenuhi persyaratan minimum. Teknik Persona yaitu mengumpulkan, menganalisis dan mensintesis informasi terkait dengan pengguna yang berinteaksi dengan sistem perangkat lunak. Teknik ini membantu memfokuskan analisis dan desain perangkat lunak pada fitur dan tujuan pengguna akhir [1].

Sudah sekitar sepuluh tahun yang lalu Rogers, Bannon dan Button [2] membuka dan membahas tiga pertanyaan ini : (1) Apa permasalahan di HCI? (2) Apa yang ditawarkan oleh pendekatan teoritis HCI? (3) Bagaimana hubungan teori dengan praktik? Dalam penelitian ini akan membahas, mendiskusi dan memberikan jawaban yang mungkin dari ketiga pertanyaan ini [3].

Dalam sebuah jurnal yang didapatkan dari referensi versi Cooper dan teknik Persona [4] dan mulai menetapkan teknik ini dalam studi kasus [5]. Sejak awal teknik ini cukup sulit diterapkan. Misalnya langkah pertama yaitu dari teknik yang direkomendasikan oleh Cooper adalah Identify Behavioral Variables. Studi pengguna yang diperlukan untuk mengekstrak variable perilaku bukanlah langkah yang langsung dan harus ditentukan dari pada disiratkan sebagai aktivitas teknik pertama. Selain itu juga beberapa teknik seperti Identifikasi Pola Perilaku Penting dan Periksa Kelengkapan dan Redudansi, gagal menentukan produk keluaran apa pun. Akhirnya, output teknik akhir tidak terkait dengan tahap persyaratan rekayasa peranglat lunak. Untuk dapat membangun Persona ke dalam pengembangan SE secara rutin perlu untuk mengidentifikasi aktivitas dan produk yang terkait dengan setiap aktivitas. Untuk masing-masing batasan yang diidentifikasi, dalam penelitian ini disusun perbaikan untuk dibangun ke dalam Persona. Dalam penelitian ini dirasa cocok untuk memilih meningkatkan versi terbaru ke teknik Persona yang diterbitan oleh Cooper [4]. Dalam penelitian ini telah dimasukkan peningkatan ke versi SE Persona. Penelitian ini terdiri dari sekelompok kegiatan dan input serta output mengarah pada penciptaan kepribadian [1].

Selain itu, dalam penelitian ini dirancang dan implementasikan alat prototype untuk mendukung teknik Persona yang diusulkan. Persona yang ditingkatkan menghindari rintangan yang dihadapi oleh pengembang perangkat lunak biasa yang tidak terbiasa dengan teknik HCI yang menerapkan Persona asli. Berdasarkan pengamatan bermanfaat untuk mengadaptasi Persona untuk diintegrasikan ke dalam proses pengembangan SE. Integrasi Persona ke tahap persyaratan SE dapat meningkatkan sebuah pemahaman tentang apa yang akan dilakukan produk perangkat lunak dan bagaimana seharusnya berperilaku. Teknik Persona muncul untuk mebantu memfokuskan analisis perangkat lunak dan kegiatan desain pada karakteristik dan tujuan pengguna akhir dan telah diperkaya proses persyaratan SE dengan memasukkan kegiatan Persona ke dalam kegiatan persyaratan. Elisitasi persyaratan dan analisis persyaratan adalah kegiatan rekayasa persyaratan yang paling dipengaruhi oleh penggabungan Persona.

\section{TINJAUAN PUSTAKA}

Adapun penelitian terkait dari sebelumnya mengenai peningkatan kebutuhan perangkat lunak yang sudah dipublikasikan, diantaranya adalah :

Penelitian yang dilakukan oleh Miaskiewicz dan Kozar, K.A pada tahun 2011. Penelitian ini membahas tentang keuntungan dari produk desain untuk persona. Tujuannya untuk melihat apakah manfaat menggabungkan persona ke dalam proses desain yang berpusat pada pengguna jelas. Hasil 
yang ditunjukkan dari penelitian ini, bahwa banyak manfaat dari menggabungkan persona dengan produk desain [6].

Selanjutnya penelitian yang dilakukan oleh Bruna Ferreire, Williamson Silva, Edson Oliveira, Tayana Conte pada tahun 2015. Tujuan untuk merancang persona dengan empati atau Empaty Map $(E M)$. Dengan merancang EM, diharapkan dapat mempermudah dalam merancang persona. Hasil penelitian ini bisa membuktikan bahwa sebagian subjek berpikir bahwa EM mudah digunakan dan bermanfaat untuk penciptaan persona [7].

Berikutnya penelitian yang dilakukan oleh Sabine dan Lene Nielsen pada tahun 2009. Penelitian ini bertujuan untuk melihat scenario persona dengan metode story telling untuk ide desain. Alasan mengapa menggunakan story telling karena kemampuan manusia yang melekat untuk membangun, menceritakan, dan menafsirkan cerita itu tidak mudah dan menyajikan cerita yang baik, dan berorientasi desain tanpa metode dukungan. Hasil yang didapat dari teori naratif menunjukkan bahwa cerita yang sejalan dengan bentuk cerita dan elemen naratif lebih mudah untuk dihubungkan, diingat dan secara umum lebih meyakinkan [8].

Selanjutnya penelitian yang dilakukan Soon-Gyo Jung, Moeed Ahmad, Jisun An, Lene Nielsen, Haewoon Kwak, Bernard J. Jansen pada tahun 2017. Mereka mengembangkan metodologi untuk generasi persona menggunakan media sosial waktu nyata untuk distribusi produk melalui platform online, dengan begitu bisa memudahkan untuk menyeleksi setiap kategori persona. Hasil yang didapatkan dari penelitian ini adalah kepribadian bisa cepat dan secara otomatis dibuat skala besar, dan menghasilkan persona yang didasarkan pada nyata data yang menceriminkan orang sesungguhnya [9].

Penelitian selanjutnya dilakukan oleh Nan Tu, Xiao Dong, Pei-Luen Patrick Rau, Tao Zhang pada tahun 2010. Dalam makalah ini digambarkan ciptaan persona proses yang menggabungkan metode kuantitatif seperti cluster analisis dengan metode kuantitatif seperti observasi dan wawancara untuk menghasilkan persona yang menyakinkan dan representatif Kemudian digambarkan proses pembuatan personas melalui studi kasus. Analisis cluster digunakan untuk mengelompokkan pengguna berdasarkan kesamaan mereka di tujuan dan preferensi pengambilan keputusan dan hasilnya adalah persona dapat dibuat menggunakan metode kuantitatif [10].

\section{METODE PENELITIAN}

Dalam proses elisitasi kebutuhan menggunakan User Persona ada tahapan yang dilakukan. Tahapan tersebut sebagai berikut [4]:

\section{State Hypotheses}

Pada tahapan pertama ini hal yang dilakukan adalah menyatakan perumusan hipotesis awal tentang kemungkinan pesona yang akan dibuat. Untuk menggali hipotesa tersebut dilakukan wawancara dan penggalian informasi melalui stakeholder [1].

\section{Identify Behavioral Variable}

Pada tahapan kedua dilakukan identifikasi dan diukur berdasarkan survey dan wawancara mendalam. Untuk dibuat karakteristik fiksi dari orang orang yang angka latar belakang untung pengguna, tujuan penggunaan, kebutuhan, sikap, pengetahuan, dan kemahiran khusus, dll [11]. Semua wawancara akan dikumpulkan untuk mengetahui motivasi dan perilaku mereka dan menghasilkan sebuah variabel.

\section{Map Interview Subjects to Behavioral Variable}

Pada tahapan ketiga ini menghasilkan subjek dari variabel-variabel berdasarkan karakteristik dan dilakukan pemetaan berdasarkan hasil wawancara sesuai skala variabel agar dalam menganalisa untuk pengelompokan sesuai varabel perilaku yang diamati.

\section{Identify Significant Behavior Patterns}

Setelah pengelompokkan variabel pada tahap sebelumnya. Selanjutnya, variabel dibuat berupa persentase agar lebih signifikan dan mengidentifikasi pola karakteristik untuk menemukan kelompok dari beberapa subjek di range tertentu. Range untuk menentukan pola karakteristik yang signifikan [12]. 


\section{Synthesize Characteristics and Relevant Goals}

Pada tahap kelima ini mengsintesis karakteristk untuk penjabaran yang lebih detail dari karakteristik responden untuk tujuan relevan dan juga menjelaskan kepribadian dari stakeholder yang telah diwawancarai dan dijabarkan dalam bentuk personas foundation document [13].

6. Check for Redudancy and Completeness

Pada tahap ini dilakukan pengecekan dari tahap pertama hingga tahap kelima sehingga mengahasilkan dokumen validasi dari pemetaan. Dokumen validasi memastikan seluruh subjek mengisi dan memvalidasi dengan menggunakan respoden lain, memvalidasi semua responden tentang variabel yang belum ada pada emotion card.

7. Expand the Description of Attributes and Behaviors

Pada tahap ini dibuat sebuah narasi untuk setiap responden agar memperjelas berdasarkan isi personas foundation document

8. Designate Persona Types

Menentukan persona primer agar kebutuhan dan tujuan menjadi target utama untuk pencapaian sistem. Sedangkan persona sekunder hanya sebagai kebutuhan tambahan.

\section{Build Use Cases}

Membuat sebuah diagram use case beranotasi dan juga membuat spesifikasi use case, Selain itu, definisi yang disaranka juga memiliki manfaat untuk pemodelan use case dengan UML dan use case model refactoring : dalam UML hubungan luas menentukan perilaku use case yang terkait [14].

10. Implement and Evaluate Prototypes

Pada tahap terakhir ini adalah membuat prototype dari diagram use case yang telah dibuat pada tahap sebelumnnya. Prototype sangat penting untuk menguji sebuah kelayakan produk yang dibuat setelah melakukan tahapan pertama sampai tahap kesembilan bertujuan untuk mengevaluasi dengan memperlihatkan hasil kepada user. Prototype ini harus bekerja cukup setiap sistem nyata yang dapat digunakan dan memecahkan masalah [15].

\section{HASIL DAN PEMBAHASAN}

Pada bagian ini diberikan hasil dan pembahasan pada masing-masing tahapan yang sudah dilakukan. Ada 10 tahapan yang sudah dilakukan dengan hasil sebagai berikut:

\section{State Hypothese}

Pada Tabel 1. peneliti membagi menjadi 2 Hipotesa yang mana diantara Mahasiswa, dan juga Dosen saling memiliki peran berdasarkan permasalahan yang diteliti.

Tabel 1. Hypotesis Persona

\begin{tabular}{lll}
\hline Hypotesis & Persona & \multicolumn{1}{c}{ Explanation } \\
\hline $\mathbf{H}_{\mathbf{0}}$ & Mahasiswa & $\begin{array}{l}\text { Mahasiswa tidak mengetahui Mata Kuliah dasar menjadi } \\
\text { syarat untuk mengambil beberapa Mata Kuliah didalam } \\
\text { pemrograman studi. }\end{array}$ \\
\hline $\mathbf{H}_{\mathbf{1}}$ & Dosen Wali & $\begin{array}{l}\text { Beberapa dosen wali tidak memberikan dorongan kepada } \\
\text { mahasiswa untuk berkonsultasi sebelum melakukan } \\
\text { pemrograman krs. }\end{array}$ \\
\hline
\end{tabular}

\section{Identify Behavioral Variable}

Pada tahap kedua peneliti mengelompokkan hasil observasi perilaku dengan variabel yang dapat megidentifikasi masalah pada penelitian ini berdasarkan skala yang dibuat. Tabel 2 mengidentifikasi perilaku persona Mahasiswa, dan Tabel 2 mengidentifikasi perilaku persona Mahasiswa dan Tabel 3 mengidentifikasi perilaku persona Dosen. 
Tabel 2. Identify Behavioral Variables (Mahasiswa)

\begin{tabular}{|c|c|}
\hline $\begin{array}{c}\text { Observed Behavioural } \\
\text { Variabel }\end{array}$ & Scale \\
\hline $\begin{array}{l}\text { Mengetahui mata kuliah } \\
\text { yang memiliki prasyarat. }\end{array}$ & Tau $\leftrightarrow$ Tidak Tau \\
\hline $\begin{array}{l}\text { Frekuensi melakukan } \\
\text { konsultasi dosen wali. }\end{array}$ & Selalu $\leftrightarrow$ Kadang-kadang $\leftrightarrow$ Tidak Pernah \\
\hline $\begin{array}{l}\text { Alasan melakukan/tidak } \\
\text { konsultasi dosen wali. }\end{array}$ & Dorongan dosen $\leftrightarrow$ Tidak Keduanya $\leftrightarrow$ Tidak Penting \\
\hline \multicolumn{2}{|c|}{ Tabel 3. Identify Behavioral Variables (Dosen) } \\
\hline $\begin{array}{c}\begin{array}{c}\text { Observed Behavioural } \\
\text { Variabel }\end{array} \\
\end{array}$ & $\begin{array}{c}\text { Scale } \\
\end{array}$ \\
\hline $\begin{array}{l}\text { Frekuensi melakukan } \\
\text { konsultasi. }\end{array}$ & Selalu $\leftrightarrow$ Sering \\
\hline $\begin{array}{l}\text { Frekuensi tidak } \\
\text { melakukan konsultasi. }\end{array}$ & Tidak Pernah $\leftrightarrow$ Kadang-kadang $\leftrightarrow$ Sering \\
\hline $\begin{array}{l}\text { Motivasi melakukan } \\
\text { konsultasi. }\end{array}$ & $\begin{array}{l}\text { Rutinitas } \leftrightarrow \text { Memberikan informasi penting } \leftrightarrow \text { Mahasiswa asal- } \\
\text { asalan ketika memprogram KRS }\end{array}$ \\
\hline $\begin{array}{l}\text { Motivasi tidak melakukan } \\
\text { konsultasi. }\end{array}$ & $\begin{array}{l}\text { Tidak Ada } \leftrightarrow \text { Mahasiswa tidak kooperatif } \leftrightarrow \text { Sibuk(alasan } \\
\text { pribadi) }\end{array}$ \\
\hline
\end{tabular}

\section{Map Interview Subjects to Behavioral Variable}

Pada tahap ketiga peneliti memetakan hasil identifikasi perilaku persona berdasarkan variabel yang telah diobservasi seperti terlihat pada Emotion Card untuk Mahasiswa pada Gambar 1.a dan untuk Dosen pada Gambar 1.b. Kemudian dikelompokkan berdasarkan respon masing-masing persona.

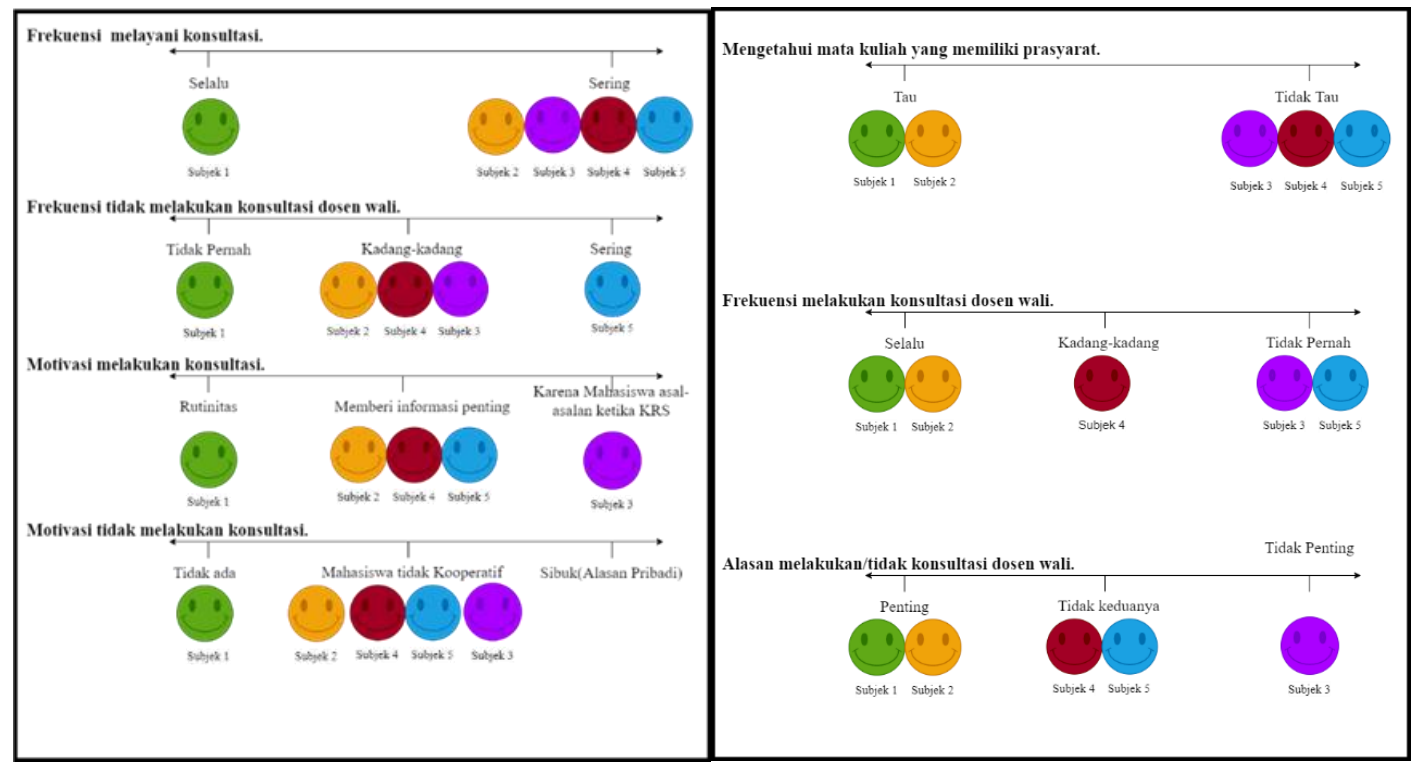

Gambar 1. Emoticon Card (a) Mahasiswa (b) Dosen

\section{Identify Significant Behavior Patterns}

Pada tahap keempat peneliti melakukan paduan terhadap jawaban responden. Yang mana kecenderungan untuk tidak melakukan konsultasi dan sebenarnya dosen sudah cukup aktif untuk melayani konsultasi. Pada Tabel 4 dan 5 menjukkan presentase berdasarkan jawaban responden pada 
setiap variabel yang diidentifikasi. Sedangkan pada Gambar 2 peneliti melakukan pengelompokan untuk mengidentifikasi responden yang konsisten ketika diidentifikasi.

Tabel 4. Percentage Grouping Table (Mahasiswa)

\begin{tabular}{|c|c|c|}
\hline Observed Behavioral Variable & Scale & Percentage (\%) \\
\hline $\begin{array}{l}\text { Mengetahui mata kuliah yang } \\
\text { memiliki prasyarat }\end{array}$ & $\begin{array}{l}\text { Tau } \\
\text { Tidak Tau }\end{array}$ & $\begin{array}{l}20 \% \\
80 \% \\
\end{array}$ \\
\hline $\begin{array}{l}\text { Frekuensi melakukan konsultasi } \\
\text { dosen wali }\end{array}$ & $\begin{array}{l}\text { Selalu } \\
\text { Kadang-kadang } \\
\text { Tidak Pernah }\end{array}$ & $\begin{array}{l}20 \% \\
20 \% \\
60 \%\end{array}$ \\
\hline $\begin{array}{l}\text { Alasan melakukan/tidak } \\
\text { konsultasi dosen wali }\end{array}$ & $\begin{array}{l}\text { Penting } \\
\text { Tidak Keduannya } \\
\text { Tidak Penting }\end{array}$ & $\begin{array}{l}20 \% \\
60 \% \\
20 \%\end{array}$ \\
\hline Tabel 5. Perce & tage Grouping Table (Doser & \\
\hline Observed Behavioral Variable & Scale & Percentage (\%) \\
\hline Frekuensi melayani konsultasi & $\begin{array}{l}\text { Selalu } \\
\text { Sering }\end{array}$ & $\begin{array}{l}20 \% \\
80 \% \\
\end{array}$ \\
\hline $\begin{array}{lll}\text { Frekuensi } & \text { tidak } & \text { melakukan } \\
\text { konsultasi } & & \end{array}$ & $\begin{array}{l}\text { Tidak Pernah } \\
\text { Kadang-kadang } \\
\text { Sering }\end{array}$ & $\begin{array}{l}20 \% \\
60 \% \\
20 \%\end{array}$ \\
\hline Motivasi melakukan konsultasi & $\begin{array}{l}\text { Rutinitas } \\
\text { Memberi informasi penting } \\
\text { Karena mahasiswa asal- } \\
\text { asalan ketika KRS }\end{array}$ & $\begin{array}{l}20 \% \\
60 \% \\
20 \%\end{array}$ \\
\hline $\begin{array}{l}\text { Motivasi } \\
\text { konsultasi }\end{array}$ tidak $\quad$ melakukan & $\begin{array}{l}\text { Tidak ada } \\
\text { Mahasiswa tidak kooperatif } \\
\text { Sibuk (alasan pribadi) }\end{array}$ & $\begin{array}{c}20 \% \\
80 \% \\
0 \%\end{array}$ \\
\hline
\end{tabular}

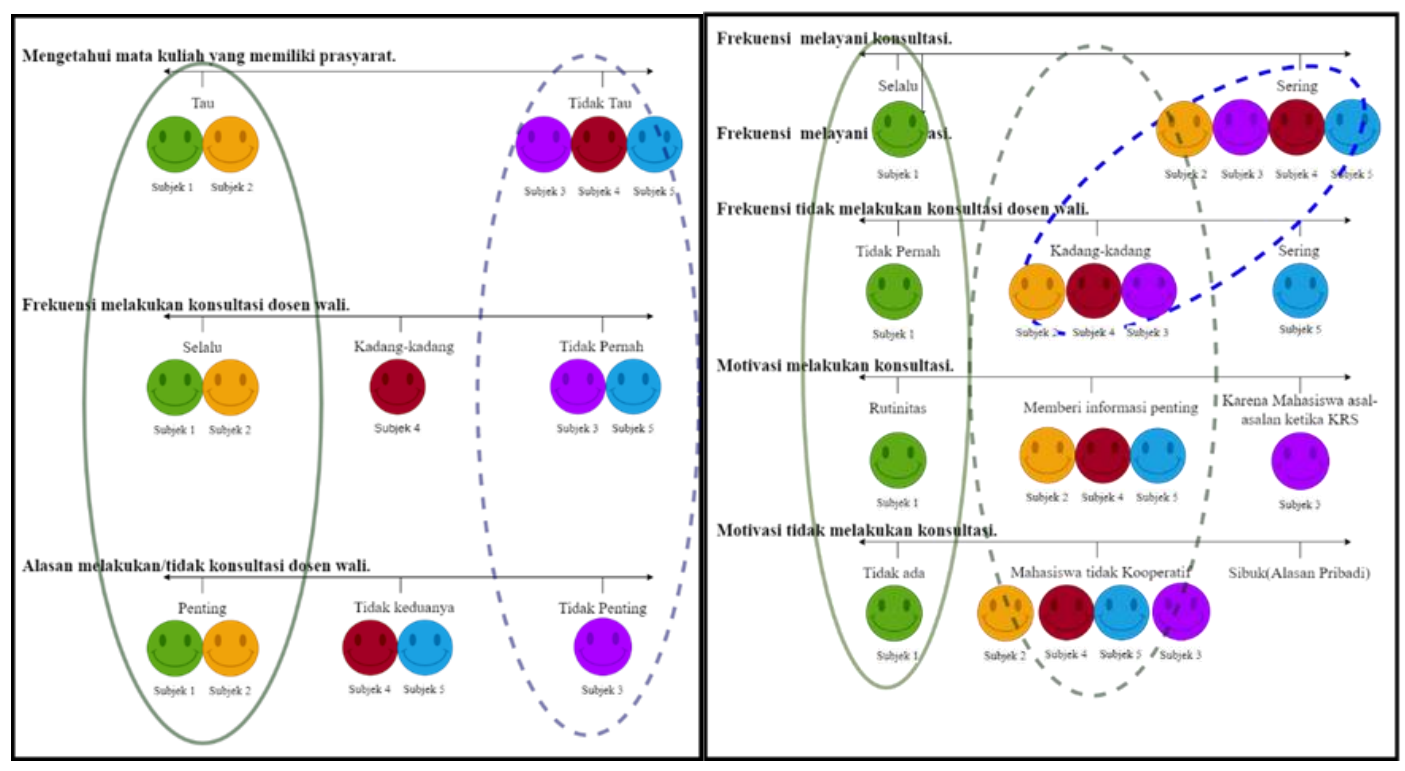

Gambar 2. Identify Significant Behaviour Patterns (A) Mahasiswa, (B) Dosen

\section{Synthesize Characteristics and Relevant Goals}

Pada tahap kelima ini peneliti melakukan observasi dan juga identifikasi karakter persona agar peneliti mengetahui responden yang konsisten dengan tujuan mereka. Identifikasi karakter dilakukan pada setiap responden seperti terlihat pada Gambar 3 dilakukan pada responden mahasiswa dan dosen. 


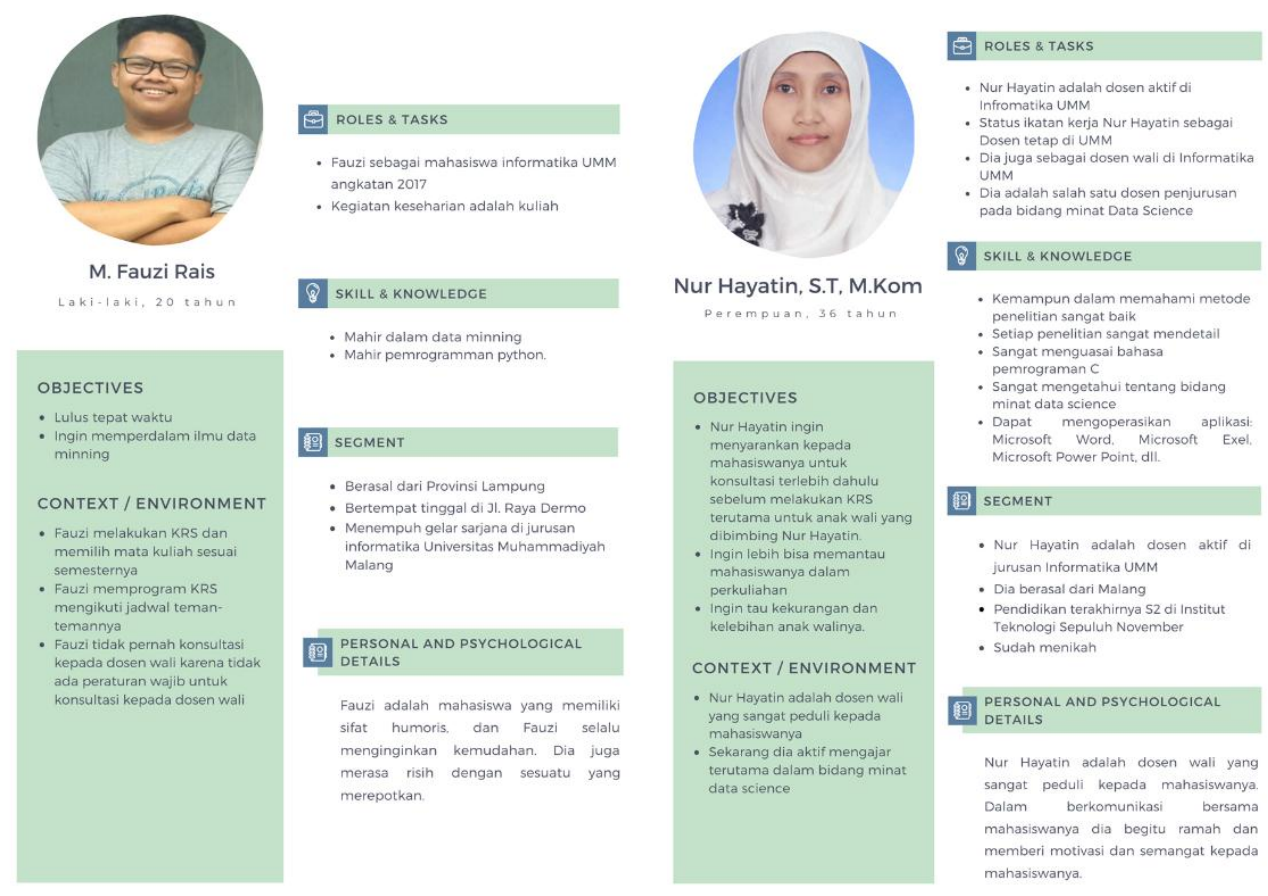

Gambar 3. Personas Foundation Document (A) Mahasiswa, (B) Dosen

\section{Check for Redudancy and Completeness}

Pada tahap keenam ini peneliti melakukan validasi agar dapat memastikan seluruh responden telah berkontribusi dengan memberikan respon atas pertanyaan yang dibuat berdasarkan hasil observasi perilaku persona pada tahap kedua.

1. Memastikan Seluruh Subject Mengisi

Tabel 6. Validasi Pengisian (Mahasiswa)

\begin{tabular}{|c|c|c|c|}
\hline Question & Interview Subject & Response & Checking \\
\hline $\begin{array}{l}\text { Semester berapakah } \\
\text { anda? }\end{array}$ & $\begin{array}{ll}- & \text { Fauzi } \\
- & \text { Alfian } \\
- & \text { Halimahtus } \\
- & \text { Wahyu } \\
- & \text { Arif }\end{array}$ & $\begin{array}{ll}- & \text { Semester } 6 \\
- & \text { Semester } 6 \\
- & \text { Semester } 8 \\
- & \text { Semester } 6 \\
- & \text { Semester } 6\end{array}$ & $\begin{array}{ll}- & \text { Sudah mengisi } \\
- & \text { Sudah mengisi } \\
- & \text { Sudah mengisi } \\
- & \text { Sudah mengisi } \\
- & \text { Sudah mengisi }\end{array}$ \\
\hline $\begin{array}{l}\text { Apakah } \\
\text { mengetahui } \\
\text { matakuliah yang } \\
\text { memiliki prasyarat } \\
\text { dalam pogram studi } \\
\text { ? }\end{array}$ & $\begin{array}{ll}- & \text { Fauzi } \\
- & \text { Alfian } \\
- & \text { Halimahtus } \\
- & \text { Wahyu } \\
- & \text { Arif }\end{array}$ & $\begin{array}{ll}\text { - } & \text { Tidak Tau } \\
\text { - } & \text { Tau } \\
\text { - } & \text { Tidak Tau } \\
\text { - } & \text { Tidak Tau } \\
\text { - } & \text { Tidak Tau }\end{array}$ & $\begin{array}{ll}- & \text { Sudah mengisi } \\
- & \text { Sudah mengisi } \\
- & \text { Sudah mengisi } \\
- & \text { Sudah mengisi } \\
- & \text { Sudah mengisi }\end{array}$ \\
\hline $\begin{array}{l}\text { Apakah anda sering } \\
\text { melakukan ataupun } \\
\text { menerima konsultasi } \\
\text { kepada dosen wali? }\end{array}$ & $\begin{array}{ll}- & \text { Fauzi } \\
- & \text { Alfian } \\
- & \text { Halimahtus } \\
- & \text { Wahyu } \\
- & \text { Arif }\end{array}$ & $\begin{array}{ll}\text { - } & \text { Tidak Pernah } \\
\text { - } & \text { Selalu } \\
\text { - } & \text { Tidak Pernah } \\
\text { - } & \text { Tidak Pernah } \\
\text { - } & \text { Kadang-Kadang }\end{array}$ & $\begin{array}{ll}- & \text { Sudah mengisi } \\
- & \text { Sudah mengisi } \\
- & \text { Sudah mengisi } \\
- & \text { Sudah mengisi } \\
- & \text { Sudah mengisi }\end{array}$ \\
\hline $\begin{array}{l}\text { Apakah alasan anda } \\
\text { melakukkan / tidak } \\
\text { melakukan } \\
\text { konsultasi } \\
\text { dosen wali? }\end{array}$ & $\begin{array}{ll}- & \text { Fauzi } \\
- & \text { Alfian } \\
- & \text { Halimahtus } \\
- & \text { Wahyu } \\
- & \text { Arif }\end{array}$ & $\begin{array}{ll}\text { - } & \text { Tidak Keduanya } \\
\text { - } & \text { Tidak Keduanya } \\
\text { - } & \text { Tidak Penting } \\
\text { - } & \text { Tidak Keduanya } \\
\text { - } & \text { Tidak Keduanya }\end{array}$ & $\begin{array}{ll}- & \text { Sudah mengisi } \\
- & \text { Sudah mengisi } \\
- & \text { Sudah mengisi } \\
- & \text { Sudah mengisi } \\
- & \text { Sudah mengisi }\end{array}$ \\
\hline
\end{tabular}


Tabel 7. Validasi Pengisian(Dosen)

\begin{tabular}{|c|c|c|c|}
\hline Question & Interview Subject & Response & Checking \\
\hline $\begin{array}{l}\text { Apakah anda sering } \\
\text { melayani mahasiswa } \\
\text { untuk melakukan } \\
\text { konsultasi? }\end{array}$ & $\begin{array}{l}\text { - Nur Hayatin } \\
\text { - Ali Sofyan } \\
\text { - Gita } \\
\text { - Christian } \\
\text { - Mahar }\end{array}$ & $\begin{array}{l}\text { - Selalu } \\
\text { - Sering } \\
\text { - Sering } \\
\text { - Sering } \\
\text { - Sering }\end{array}$ & $\begin{array}{l}\text { - Sudah mengisi } \\
\text { - Sudah mengisi } \\
\text { - Sudah mengisi } \\
\text { - Sudah mengisi } \\
\text { - Sudah mengisi }\end{array}$ \\
\hline $\begin{array}{lr}\text { Apakah anda sering } \\
\text { tidak } \\
\text { mahasiswa melayani } \\
\text { melakukan } \\
\text { konsultasi ? }\end{array}$ & $\begin{array}{l}\text { - Nur Hayatin } \\
\text { - Ali Sofyan } \\
\text { - Gita } \\
\text { - Christian } \\
\text { - Mahar }\end{array}$ & $\begin{array}{l}\text { - Tidak Tau } \\
\text { - Kadang-kadang } \\
\text { - Kadang-kadang } \\
\text { - Kadang-kadang } \\
\text { - Sering }\end{array}$ & $\begin{array}{l}\text { - Sudah mengisi } \\
\text { - Sudah mengisi } \\
\text { - Sudah mengisi } \\
\text { - Sudah mengisi } \\
\text { - Sudah mengisi }\end{array}$ \\
\hline $\begin{array}{lr}\text { Apakah } & \text { yang } \\
\text { membuat } & \text { anda } \\
\text { termotivasi } & \text { untuk } \\
\text { melakukan } & \\
\text { konsultasi ? } & \end{array}$ & $\begin{array}{l}\text { - Nur Hayatin } \\
\text { - Ali Sofyan } \\
\text { - Gita } \\
\text { - Christian } \\
\text { - Mahar }\end{array}$ & $\begin{array}{l}\text { - Rutinitas } \\
\text { - Memberi info } \\
\text { penting } \\
\text { - Memberi info } \\
\text { penting } \\
\text { - Memberi info } \\
\text { penting } \\
\text { - Karena mahasiswa } \\
\text { asal-asalan }\end{array}$ & $\begin{array}{l}\text { - Sudah mengisi } \\
\text { - Sudah mengisi } \\
\text { - Sudah mengisi } \\
\text { - Sudah mengisi } \\
\text { - Sudah mengisi }\end{array}$ \\
\hline $\begin{array}{lr}\text { Apakah } & \text { yang } \\
\text { membuat } & \text { anda } \\
\text { termotivasi r untuk } \\
\text { tidak melakukan } \\
\text { konsultasi ? }\end{array}$ & $\begin{array}{l}\text { - Nur Hayatin } \\
\text { - Ali Sofyan } \\
\text { - Gita } \\
\text { - Christian } \\
\text { - Mahar }\end{array}$ & $\begin{array}{l}\text { - Tidak Ada } \\
\text { - Mahasiswa tidak } \\
\text { kooperatif } \\
\text { - Mahasiswa tidak } \\
\text { kooperatif } \\
\text { - Mahasiswa tidak } \\
\text { kooperatif } \\
\text { - Mahasiswa tidak } \\
\text { kooperatif }\end{array}$ & $\begin{array}{l}\text { - Sudah mengisi } \\
\text { - Sudah mengisi } \\
\text { - Sudah mengisi } \\
\text { - Sudah mengisi } \\
\text { - Sudah mengisi }\end{array}$ \\
\hline
\end{tabular}

2. Memvalidasi dengan responden lain

Tabel 8. Validasi Responden Lain

\begin{tabular}{|c|c|c|c|}
\hline Question & Interview Subject & Response & Checking \\
\hline $\begin{array}{l}\text { Semester berapakah } \\
\text { anda? }\end{array}$ & $\begin{array}{ll}- & \text { Lutfi } \\
- & \text { Ipin }\end{array}$ & $\begin{array}{ll}- & \text { Semester } 6 \\
- & \text { Semester } 6\end{array}$ & $\begin{array}{l}\text { Sama } \\
\text { responden } \\
\text { sebelumnya }\end{array}$ \\
\hline $\begin{array}{l}\text { Apakah } \\
\text { mengetahui } \\
\text { matakuliah } r \text { yang } \\
\text { memiliki prasyarat } \\
\text { dalam pogram studi } \\
\text { ? }\end{array}$ & $\begin{array}{ll}- & \text { Lutfi } \\
- & \text { Ipin }\end{array}$ & $\begin{array}{lr}\text { - } & \text { Tidak Tau } \\
\text { - } & \text { Tidak Tau }\end{array}$ & $\begin{array}{l}\text { Sama seperti subjek } \\
3,4 \text {, dan } 5\end{array}$ \\
\hline $\begin{array}{l}\text { Apakah anda sering } \\
\text { melakukan ataupun } \\
\text { menerima konsultasi } \\
\text { kepada dosen wali? }\end{array}$ & $\begin{array}{ll}- & \text { Lutfi } \\
- & \text { Ipin }\end{array}$ & $\begin{array}{ll}- & \text { Tidak Pernah } \\
\text { - } & \text { Kadang - Kadang }\end{array}$ & $\begin{array}{l}\text { Sama } \text { seperti subjek } \\
5 \\
\text { Sama } \\
4\end{array}$ \\
\hline $\begin{array}{l}\text { Apakah alasan anda } \\
\text { melakukkan / tidak } \\
\text { melakukan } \\
\text { konsultasi kepada } \\
\text { dosen wali ? }\end{array}$ & $\begin{array}{ll}- & \text { Lutfi } \\
- & \text { Ipin }\end{array}$ & $\begin{array}{ll}\text { - } & \text { Tidak keduanya } \\
\text { - } & \text { Tidak keduanya }\end{array}$ & $\begin{array}{l}\text { Sama seperti } \\
\text { subjek4, dan } 5\end{array}$ \\
\hline
\end{tabular}


Tahap pertama dari fase Check for Redudancy and Completeness adalah memastikan bahwa seluruh responden telah melengkapi hasil Emotion Card yang diberikan, hal tersebut berguna untuk memastikan tidak ada parameter yang hilang dari setiap responden. Fase tersebut dilakukan untuk seluruh responden baik untuk Mahasiswa seperti terlihat pada Tabel 6 dan pada Dosen seperti terlihat pada Tabel 7. Pada setiap validasi yang dilakukan dianalisa hasil jawaban sehingga jawaban bukan hanya sudah atau belum diisi namun juga dipastikan bahwa jawaban relevan dengan pertanyaan.

Setelah menyelesaikan tahap pertama dari fase Check for Redudancy and Completeness selanjutnya hasil dari Emotion Card divalidasi dengan responden lain yang tidak berkaitan dari setiap fase yang ada dilakukan pada tahap sebelumnya. Responden yang diambil pada fase ini diambil secara acak dengan ketentuan merupakan populasi yang sama dengan responden pada fase sebelumnya. Tabel 8 menunjukkan bahwa responden mengisi item yang sama dengan responden utama.

\section{Expand the Description of Attributes and Behaviors}

Pada tahap ketujuh ini peneliti menjabarkan kembali atribut dan perilaku setiap persona berdasakan informasi yang didapat pada tahap-tahap sebelumnya. Atribut dan perilaku yang ditunjukkan melalui emotion card selanjutnya dibuat dalam bentuk narasi yang menggambarkan keseluruhan masalah yang dihadapi oleh pengguna. Dalam penelitian yang dilakukan seperti terlihat pada Tabel 9 diambil beberapa responden untuk diambil persona dari masing-masing atribut tersebut.

Tabel 9. Narasi Persona

Nama

Deskripsi

Muhammad Fauzi Rais $\quad$ Fauzi (20) mahasiswa informatika angkatan 2017

yang sekrang berada di semester 6. Fauzi berasal dari pulau Lampung, kini ia sedang mendalami pada matakuliah database.

Fauzi melakukan KRS dan memilih mata kuliah sesuai sks di semesternya, mengambil matakuliah yang di wajbkan dan mengambil matakuliah yang di luar sks jika masih memungkinkan, dia juga memprogram KRS mengikuti jadwal temantemannya. Dan Fauzi tidak pernah konsultasi kepada dosen wali karena tidak ada peraturan wajib untuk konsultasi kepada dosen wali

\begin{tabular}{ll}
\hline Nama & Deskripsi \\
\hline Nur Hayatin, S.T, M.Kom & Nur Hayatin (36) adalah seorang dosen aktif di \\
& informatika UMM, Nur Hayatin juga sebagai \\
& dosen wali di informatika, dia sangat \\
& memperhatikan mahasiswanya, Nur Hayatin \\
& adalah salah satu dosen dalam bidang minat Data \\
& Science, kemampuan iNur Hayatin dan program \\
& sangat handal dan juga sangat handal dalam \\
metode penelitian. Nur Hayatin sebagai dosen \\
wali ingin menyarankan kepada mahasiswa untuk \\
konsultasi terlebih dahulu sebelum melakukan \\
KRS terutama untuk anak wali yang dibimbing \\
Nur Hayatin.
\end{tabular}

\section{Designate Persona Types}

Pada tahap kedelapan ini peneliti mengambil sample persona yang memiliki tipe perilaku paling mencolok. Didapati ada mahasiswa yang tidak menjumpai masalah seperti yang diangkat dalam penelitian ini dikarenakan keaktifan mahasiswa tersebut. Sedangkan ada 
persona dari dosen yang begitu aktif mengajak mahasiswanya agar selalu berkonsultasi serta memberi motivasi ke mahasiswanya.

\section{Designate Persona Types : Mahasiswa}

PRIMARY PERSONA : Muhammad Fauzi Rais, Seorang Mahasiswa Aktif Informatika Fauzi (20) mahasiswa informatika angkatan 2017 yang sekrang berada di semester 6. Fauzi berasal dari pulau Lampung, kini ia sedang mendalami pada mata kuliah database.

Fauzi melakukan KRS dan memilih mata kuliah sesuai sks di semesternya, mengambil matakuliah yang di wajbkan dan mengambil matakuliah yang di luar sks jika masih memungkinkan, dia juga memprogram KRS mengikuti jadwal teman-temannya. Dan Fauzi tidak pernah konsultasi kepada dosen wali karena tidak ada peraturan wajib untuk konsultasi kepada dosen wali

\section{Designate Persona Types : Dosen}

\section{PRIMARY PERSONA : Nur Hayatin, S.T, M.Kom, Dosen Informatika UMM}

Nur Hayatin (36) berasal dari Malang pendidikan terakhirnya S2 di Institut Teknologi Sepuluh Nopember sekarang beliau adalah seorang dosen tetap di informatika UMM dan Nur Hayatin juga sebagai dosen wali di informatika, dia sangat memperhatikan sangat peduli kepada mahasiswanya, sekarang Nur Hayatin aktif mengajar terutama dalam bidang minat data science, kemampuan Nur Hayatin dan program sangat handal dan juga sangat handal dalam metode penelitian beliau sangat teliti dan detail dalam penelitian. Nur Hayatin sangat menguasai bahasa pemrograman $\mathrm{C}$.

Sebagai dosen wali ingin menyarankan kepada mahasiswa untuk konsultasi terlebih dahulu sebelum melakukan KRS terutama untuk anak wali yang dibimbing, Nur Hayatin adalah dosen wali yang sangat peduli kepada mahasiswanya. Dalam berkomunikasi bersama mahasiswanya dia begitu ramah dan memberi motivasi dan semangat kepada mahasiswanya dan ingin tau kekurangan dan kelebihan anak walinya dan ingin lebih bisa memantau mahasiswanya dalam perkulihan.

\section{Build Use Cases}

Membuat use case berdasarkan identifikasi kebutuhan PL dengan informasi kebutuhan yang telah digali pada penelitian ini. Gambar 4 merupakan hasil dari rancangan sistem yang didapati sesuai kebutuhan persona. Kemudian pada Tabel 10 dijelaskan bagaimana persona berinteraksi melalui sistem yang telah dirancang.

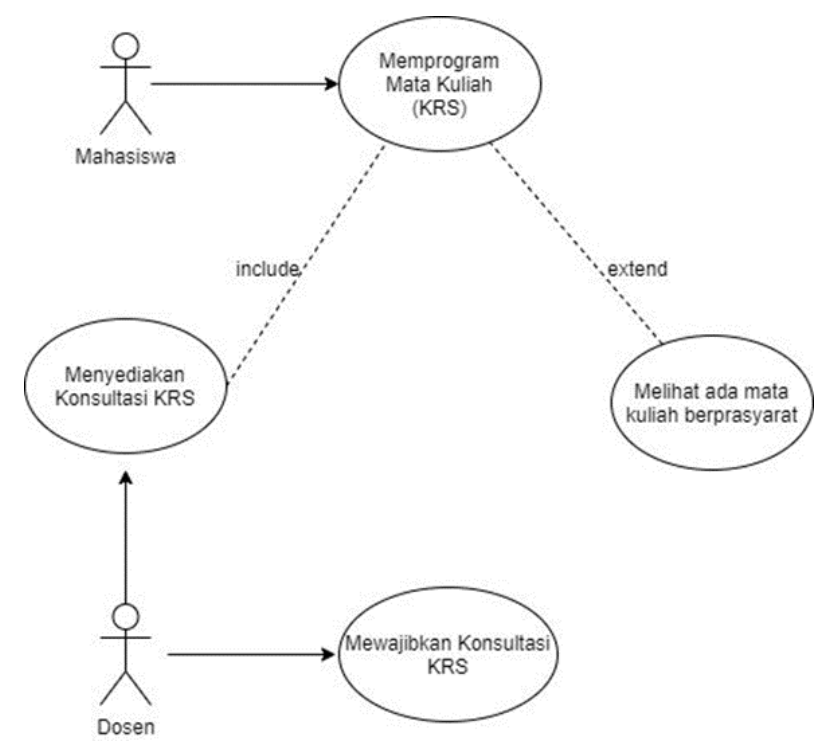

Gambar 4. Use Case Diagram 
Tabel 10. Use Case Descriptor

\begin{tabular}{|c|c|c|}
\hline Actor & Persona Type & Description \\
\hline \multirow{6}{*}{ Dosen } & \multirow{6}{*}{ Primary : Nur Hayatin, S.T, M.Kom } & Setelah melakukan login di website \\
\hline & & \multirow{5}{*}{$\begin{array}{l}\text { INFOKHS, Nur Hayatin } \\
\text { menginginkan mahasiswa } \\
\text { berkonsultasi terlebih dahulu } \\
\text { tentang mata kuliah yang akan } \\
\text { diambil oleh mahasiswanya } \\
\text { sebelum memprogram mata kuliah } \\
\text { (KRS) }\end{array}$} \\
\hline & & \\
\hline & & \\
\hline & & \\
\hline & & \\
\hline \multirow[t]{7}{*}{ Mahasiswa } & \multirow[t]{7}{*}{ Primary : Muhammad Fauzi Rais } & Setelah melakukan login di website \\
\hline & & INFOKHS, Fauzi melakukan \\
\hline & & konsultasi dengan dosen walinya \\
\hline & & mengenai kemampuan dia dan \\
\hline & & berdiskusi tentang mata kuliah \\
\hline & & berprasyarat, lalu dia memprogram \\
\hline & & KRS sesuai diskusi. \\
\hline
\end{tabular}

\section{Implement and Evaluate Prototypes}

Pada tahap kesepuluh dihasilkan prototipe yang telah dibut berdasarkan use case yang telah dirancang. Gambar 5 merupakan prototipe hasil implementasi rancangan.

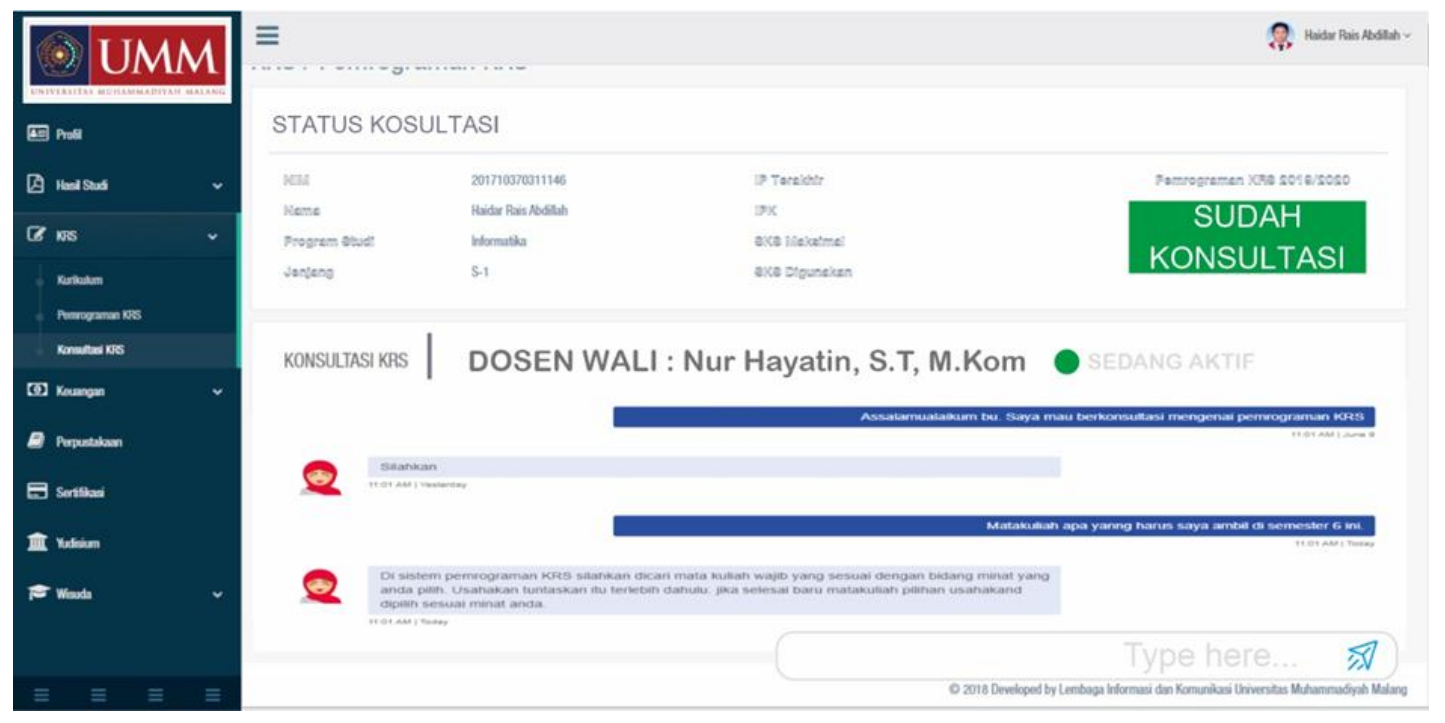

Gambar 5. Prototype

\section{KESIMPULAN}

Dari penelitian yang dilakukan, mengidentifikasi persona untuk menggali kebutuhan dapat menyelesaikan beberapa permasalahan yang dapat digali dengan lebih detail. Beberapa tahap yang dilakukan pada metode tersebut terbukti unggul dibandingkan hanya satu tahap yang biasa dilakukan pada penggalian kebutuhan pada umumnya, namun demikian hal tersebut juga berkorelasi dengan lamanya waktu yang dibutuhkan pada saat fase penggalian kebutuhan. Dalam penelitan yang dilakukan penggalian kebutuhan dengan metode tersebut dapat menggali bahwa kebanyakan dosen sudah cukup aktif dalam melayani mahasiswa untuk konsultasi. Sedangkan mahasiswa masih cenderung meremehkan manfaat jika berkonsultasi dan akibat jika tidak berkonsultasi terlebih dahulu. Dengan pendekatan persona peneliti dapat merancang sistem dengan $\mathrm{HCI}$ yang lebih efektif sehingga menghasilkan PL yang berkualitas. 


\section{REFERENSI}

[1] S. T. Acuña, J. W. Castro, and N. Juristo, "A HCI technique for improving requirements elicitation," Inf. Softw. Technol., vol. 54, no. 12, pp. 1357-1375, Dec. 2012, doi: 10.1016/J.INFSOF.2012.07.011.

[2] G. Rogers, Yvonne and Bannon, Liam and Button, "Rethinking theoretical frameworks for HCI: report on an INTERCHI'93 workshop, Amsterdam, 24--25th April, 1993," ACM SIGCHI Bull., vol. 26, pp. 28--30, 1994.

[3] M. Rauterberg, "HCI as an engineering discipline: to be or not to be!?," African J. Inf. Commun. Technol., vol. 2, no. 4, pp. 163-184, 2006, doi: 10.5130/ajict.v2i4.365.

[4] D. Cooper, Alan and Reimann, Robert and Cronin, About face 3: the essentials of interaction design. John Wiley $\backslash \&$ Sons, 2007.

[5] J. Castro, "Extensión de la Técnica Personas para su Incorporación en la Actividad de Análisis del Proceso de Ingeniería del Software," Trab. Fin Máster, Esc. Politécnica Super. Informática, Univ. Autónoma Madrid, 2009.

[6] T. Miaskiewicz and K. A. Kozar, "Personas and user-centered design: How can personas benefit product design processes?," Des. Stud., vol. 32, no. 5, pp. 417-430, 2011, doi: 10.1016/j.destud.2011.03.003.

[7] B. Ferreira, W. Silva, E. Oliveira, and T. Conte, "Designing personas with empathy map," Proc. Int. Conf. Softw. Eng. Knowl. Eng. SEKE, vol. 2015-Janua, pp. 501-505, 2015, doi: 10.18293/SEKE2015-152.

[8] S. Madsen and L. Nielsen, "Exploring persona-scenarios - Using storytelling to create design ideas," IFIP Adv. Inf. Commun. Technol., vol. 316, pp. 57-66, 2010, doi: 10.1007/978-3-64211762-6_5.

[9] S. G. Jung, J. An, H. Kwak, M. Ahmad, L. Nielsen, and B. J. Jansen, "Persona generation from aggregated social media data," Conf. Hum. Factors Comput. Syst. - Proc., vol. Part F1276, pp. 1748-1755, 2017, doi: 10.1145/3027063.3053120.

[10] N. Tu, X. Dong, P. L. P. Rau, and T. Zhang, "Using cluster analysis in persona development," SCMIS 2010 - Proc. 2010 8th Int. Conf. Supply Chain Manag. Inf. Syst. Logist. Syst. Eng., 2010.

[11] G. Kim, "Develop the System for the protection of valuable contents."

[12] T. Miaskiewicz, T. Sumner, and K. A. Kozar, "A Latent Semantic Analysis methodology for the identification and creation of personas," Conf. Hum. Factors Comput. Syst. - Proc., no. July 2014, pp. 1501-1510, 2008, doi: 10.1145/1357054.1357290.

[13] S. Bagriyanik and D. Karahoca, "System analyst expectations from requirements engineering tools: A human computer interaction perspective," Glob. J. Comput. Sci., vol. 04, no. 1, pp. 716, 2014.

[14] P. Metz, J. O'Brien, and W. Weber, "Specifying use case interaction: Types of alternative courses," J. Object Technol., vol. 2, no. 2, pp. 111-131, 2003, doi: 10.5381/jot.2003.2.2.a1.

[15] W. A. Rahim, W. M. Isa, A. M. Lokman, N. F. Taharim, and N. D. Wahid, "Engineering mlearning using agile user-centered design," Proc. - 2014 8th Int. Conf. Next Gener. Mob. Appl. Serv. Technol. NGMAST 2014, pp. 60-65, 2014, doi: 10.1109/NGMAST.2014.46. 